\title{
PREVALENCE OF NEWLY DIAGNOSED PREDIABETES, DIABETES MELLITUS AMONG THE OFFICERS FROM PHUOC LONG DISTRICT OF BINH PHUOC PROVINCE
}

\author{
Le Thanh Long ${ }^{1}$, Hoang Trung Vinh ${ }^{2}$ \\ 1. Phuoc Long Health Center - Binh Phuoc \\ 2. Military Medical University
}

DOI: $10.47122 / v j d e .2020 .40 .4$

\section{ABSTRACT \\ Prevalence of newly diagnosed prediabetes, diabetes mellitus among the civil servant from Phuoc Long district of Binh Phuoc province}

Objective: To evaluate the prevalence of newly diagnosed prediabetes, diabetes mellitus among the officers from Phuoc Long district of Binh Phuoc province. Subjects and methods: 268 personals communications service was examined the impaired fasting glucose $\left(\mathrm{G}_{0}\right)$; impaired glucose tolerance $\left(\mathrm{G}_{2}\right)$ anh $\mathrm{HbA}_{1}$ c. Results: Prevalence of prediabetes, type 2 diabetes mellitus by $\mathrm{G}_{0}$, $\mathrm{G}_{2}, \mathrm{HbA}_{1} \mathrm{c}$ as follows $16,0 \% ; 13,1 \% ; 17,9 \%$ and $3,8 \% ; 6,7 \% ; 2,2 \%$. Common prevalence of prediabetes in 26,9\%; type 2 diabetes mellitus in 7,1\%. Conclusion: Personal communications service from Phuoc Long district have percentage of prediabetes higher compared to type 2 diabetes mellitus which of prediabetes was diagnosed by $\mathrm{HbA}_{1} \mathrm{c}$ which takes up the highest percentage; diabetes mellitus was diagnosed by $\mathrm{G}_{2}$ which takes up the highest percentage.

Keywords: Prediabetes, type 2 diabetes mellitus, impaired glucose tolerance.

Main correspondence: Hoang Trung Vinh

Submission date: $1^{\text {st }}$ May 2020

Revised date: $16^{\text {th }}$ May 2020

Acceptance date: $27^{\text {th }}$ June 2020

Email: hoangvinh.hvqy@gmail.com

\section{INTRODUCTION}

The rates of diabetes and diabetes are increasing rapidly in the community, belonging to different age groups and subjects. In general, about $50 \%$ of patients with type 2 diabetes are diagnosed in their late stage, it is likely to be much higher when it comes to prediabetes.In the early stage of most diabetes and prediabetes cases, there is no complication, silent manifestations make it difficult for both patients and healthcare providers to detect the disease in time. In the community, there are many subjects at high risk to diabetes and diabetes, including officers with related characteristics.Screening for diabetes, diabetes in the community can be based on three methods including fasting blood glucose test, second hour blood glucose of oral glucose tolerance test and HbAlc. Each indicator gives a different result, either alone or in combination. Our research target is: to assess the prevalence of prediabetes and type 2 diabetes which are first diagnosed by fasting glucose level, oral glucose tolerance test and HbAlC among officers of Phuoc Long district.

\section{STUDY SUBJECTS AND METHODS}

1.1. Subjects: 268 officers from different departments of Phuoc Long district who had their health followed up at Medical centers are the study subjects selected according to descriptive epidemiological formula.

\subsubsection{Selection criteria}

+ Officers in different age groups are working in different departments of the district.

+ Both women and men are acceptable

+ Selected randomly from all officers of the district.

+ Agree to participate in the research

\subsubsection{Exclusion criteria}

+ Subjects who had been diagnosed with prediabetes, type 2 diabetes or other type of diabetes before.

+ Subjects with current acute diseases

+ Subjects who suffer from chronic 
diseases such as cirrhosis, kidney failure, hypothyroidism, current or previously use of corticoids, chronic pancreatic disease.

\subsection{Methods}

+ Study design: prospective, descriptive, cross-sectional.

+ Location and time conducted: Phuoc Long district medical center, from August 2017 to March 2018.

\subsubsection{Research steps}

+ Step 1: Organizing activities. Based on the list of officers from district departments to randomly select research subjects.

+ Step 2: Organize training and guidance for healthcare providers to participate in screening

\subsubsection{Research diagnostic criteria}

activities related to the implementation.

+ Step 3: Notify to-be-screened subjects about the preparation, time, location.

+ Step 4: Organize the implementation at the medical center.

+ Step 5: Summarize and analyze the data

\subsubsection{Researh content}

+ Ask for general health history, measure height, weight, calculate body mass index.

+ Test for fasting venous glucose level and $\mathrm{HbA} 1 \mathrm{c}$ then perform oral glucose tolerance test with $75 \mathrm{~g}$ of anhydride sugar mixed with $250 \mathrm{ml}$ of cool boiled water, drink in 5 minutes. Re-test for the venous glucose level after 2 hours.

Table 1.1. Research diagnostic criteria for prediabetes and type 2 diabetes

\begin{tabular}{|c|c|c|c|}
\hline & Diagnosis & Timepoint & Glucose (mmol/l) \\
\hline \multirow{3}{*}{\multicolumn{2}{|c|}{ Diabetes }} & Fasting & $\geq 7$ \\
\hline & & Random or 2-h PG during OGTT & $\geq 11.1$ \\
\hline & & $\mathrm{HbA1c}$ & $\geq 6.5 \%$ \\
\hline \multirow{4}{*}{$\begin{array}{l}\text { Prediabe } \\
\text { tes }\end{array}$} & $\begin{array}{l}\text { Impaired glucose } \\
\text { tolerance (IGT) }\end{array}$ & $\begin{array}{c}\text { - Fasting } \\
\text { - 2-h PG during OGTT }\end{array}$ & $\begin{array}{c}<5.6 \\
7.8-11.0\end{array}$ \\
\hline & $\begin{array}{l}\text { Impaired fasting } \\
\text { glucose (IFG) }\end{array}$ & $\begin{array}{c}\text { - Fasting } \\
\text { - 2-h PG during OGTT }\end{array}$ & $\begin{array}{c}5.6-6.9 \\
<7.8\end{array}$ \\
\hline & $\mathrm{HbA}_{1} \mathrm{c}$ & & $5.7-6.4 \%$ \\
\hline & $\begin{array}{l}\text { Combination of IGT. } \\
\text { IFG and } \mathrm{HbA} 1 \mathrm{C}\end{array}$ & $\begin{array}{c}\text { - Fasting } \\
\text { - 2-h PG during OGTT } \\
-\mathrm{HbA}_{1} \mathrm{c}\end{array}$ & $\begin{array}{c}5.6-6.9 \\
7.8-11.0 \\
5.7-6.4 \%\end{array}$ \\
\hline
\end{tabular}

Data was processed by PSS 17.0. Research content did meet any criteria of medical ethics.

\section{RESULTS}

Table 2.1. Age and gender proportion $(n=268)$

\begin{tabular}{|l|c|c|}
\hline \multicolumn{1}{|c|}{ Age (Years) } & Number (n) & Proportion \\
\hline$<40$ & 140 & 52.2 \\
\hline $40-49$ & 50 & 18.7 \\
\hline $50-59$ & 71 & 26.5 \\
\hline$\geq 60$ & 7 & 2.6 \\
\hline Male & 111 & 41.5 \\
\hline Female & 157 & 58.5 \\
\hline
\end{tabular}

+ Subjects below 40 years old take up the highest proportion.

+ Subjects older than 60 account for the smallest proportion.

+ Females make up for a larger proportion than males 
Table 2.2. Proportion based on laboratory indicators $(\mathrm{n}=268)$

\begin{tabular}{|l|c|c|c|}
\hline & $\mathbf{G}_{\mathbf{0}}$ & $\mathbf{G}_{\mathbf{2}}$ & $\mathbf{H b A}_{\mathbf{1}} \mathbf{c}$ \\
\hline Normal & $215(80.2 \%)$ & $215(80.2 \%)$ & $214(79.9 \%)$ \\
\hline Prediabetes & $43(16.0 \%)$ & $35(13.1 \%)$ & $48(17.9 \%)$ \\
\hline Type 2 Diabetes & $10(3.8 \%)$ & $18(6.7 \%)$ & $6(2.2 \%)$ \\
\hline
\end{tabular}

+ Subjects diagnosed with prediabetes by HbA1C has the highest proportion.

+ Subjects diagnosed with type 2 diabetes by G2 accounts for the largest proportion.

Table 2.3. Proportion based on glucose level and HbA1C $(n=268)$

\begin{tabular}{|l|c|c|}
\hline & Number (n) & Proportion (\%) \\
\hline Normal & 177 & 60.0 \\
\hline Prediabetes & 72 & 26.9 \\
\hline Type 2 Diabetes & 19 & 7.1 \\
\hline
\end{tabular}

The rate of prediates is higher than type 2 diabetes.

Table 2.4. Number of diagnostic criteria for prediabetes and type 2 diabetes

\begin{tabular}{|c|c|c|}
\hline Number of diagnostic criteria & Prediabetes $(\mathbf{n = 7 2})$ & Type 2 diabetes $(\mathbf{n}=\mathbf{1 9})$ \\
\hline 1 & $40(55.6 \%)$ & $7(36.8 \%)$ \\
\hline 2 & $25(34.7 \%)$ & $9(47.4 \%)$ \\
\hline 3 & $7(9.7 \%)$ & $3(15.8 \%)$ \\
\hline
\end{tabular}

+ Subjects with 1 criterion for prediabetes account for the largest proportion.

+ Subjects with 2 criteria for type 2 diabetes account for the largest proportion.

\section{DISCUSSIONS}

Based on the results, it was found that among the screening subjects, $7.1 \%$ of cases were first diagnosed with diabetes. These are clearly cases of early diagnosis. Prediabetes manifests $26.9 \%$ of the diagnostic criteria. In fact, if we only consider the proportion of type 2 diabetes which is diagnosed for the first time by screening among officers from different age groups, mainly below 60, this is a high proportion. Even the proportion of prediabetes $(26.9 \%)$ is not a low rate. However, in comparision with other researchs on the rate of first diagnosed prediabetes and type 2 diabetes, it is not easy to determine whether this is a high or low rate as the subjects range among researchs. There is scarcely any writer who had similar subjects to ours. Most recent epidemiologic researches have studied concurrently on the rate of both diabetes and prediabetes in the community, to reflect the cause and effect relationships. Phan Hướng Dương et al. who investigated in a number of districts in Hai Phom from 2012 to 2014 showed the rate of $5.2 \%$ for type 2 diabetes and $26.8 \%$ for prediabetes [3]. Trần Ngọc Thanh who studied on prediabetes among students and Ho Chi Minh university of Pharmacy showed that: $1.7 \%$ cases were type 2 diabetes, $16.1 \%$ were increased fasting glucose level, impaired glucose tolerance took up 23.4\%[7]. Phan Long Nhơn et al. found that in Bong Son hospital (Binh Dinh), up to $53.38 \%$ prediabetes cases had not been [6]. Nguyễn Văn Lành in 2014 showed that the rate of type 2 diabetes in Khmer people older in Hau Giang province was $17.91 \%$ and $11.91 \%$ [4]. Nguyễn Thy Khuê et al who studied on epidemiologic characteristics of glucose disorders in officers of district 10 in Ho Chi Minh city in reported a rather high rate, with $5.3 \%$ for type 2 diabetes, $9.2 \%$ for IFG, $48.2 \%$ of which were firstly diagnosed [5]. In 2001, In a large scale research on epidemiology of diabetes in Viet Nam according to international criteria, national hospital of endocrinology conducted surveys on subjects aged between 30 and 64 in 4 big 
cities: Ha Noi, Hai Phong, Da Nang and Ho Chi Minh.

The result showed that the rate of impaired glucose tolerane was $5.1 \%$. In 2002, national hospital of endocrinology conducted a nationwide survey and the result showed that the rates of impaired glucose level and impaired fasting glucose were $7.3 \%$ and $1.9 \%$ respectively, these rates in the mountainous areas are $7.1 \%$ and the plain: $7.0 \%$ and $1.4 \%$, the midlands and coastal areas: $8.3 \%$ and $2.4 \%$ and the city : $6,5 \%$ và $1,8 \%$ [2]. In a study of 2700 people aged 30-64 years old in Kien Giang province in 2004, the results showed that the prevalence of IFG was $4.1 \%$ and that of IGT was $10.7 \%$. The rate of impaired glucose tolerance in women is $12.1 \%$, higher than that of male at $8.3 \%$ but it is not statistically significant with $p>0.05$ [1]. As mentioned above, screening and diagnosis of diabetes and pre-diabetes include 3 forms: basing on fasting blood glucose, glucose tolerance test and HbAc. Each of these measures has its own diagnostic criteria, which are equivalent to each other, although it can be said that the oral glucose tolerance test seems to give more objective results.

Therefore, even if the subject only meets at least one corresponding standard, it has been identified as pre-diabetes or diabetes. Analysis of cases diagnosed with prediabetes, type 2 diabetes shows that: subjects diagnosed with prediabetes by one criterion accounts for the highest percentage, followed by 2 criteria.There are 7 cases that simultaneously met all 3 criteria. Among subjects diagnosed with type 2 diabetes, the number of cases satisfying 2 criteria accounted for the highest rate, followed by the satisfaction of 1 criterion. Subjects with type 2 diabetes meeting all the 3 criteria were seen in $15.8 \%$ cases.

Diagnostic criteria differs as the standards of different association range. The World Health Organization mainly promotes the diagnosis of pre-diabetes and type 2 diabetes based on fasting glucose test and oral glucose tolerance test.

\section{CONCLUSION}

+ The rate of diabetes was $7.1 \%$; prediabetes was $26.9 \%$.

+ Type 2 diabetes diagnosis was predominantly based on G2

$+\quad$ Prediabetes diagnosis was predominantly based on $\mathrm{HbA} 1 \mathrm{C}$

+ Prediabetes satisfying 1 diagnostic criterion accounted for the largest proportion

+ Type 2 diabetes meeting 2 diagnostic criteria made up for the largest proportion.

\section{REFERENCES}

1. Ta Van Binh et al. (2012): "Epidemiologic features of diabetes in Viet Nam. Method of treatment and prevention." - Typical scientific researches of national project carried out at Endocrine hospital. - Medical Publishing House.

2. Ta Van Binh et al. (2012). "Report on epidemiologic features of diabetes,risk factors and related problems to diabetes management nationwide" - Typical scientific researches of national project carried out at Endocrine hospital. Medical Publishing House.

3. Phan Huong Duong (2016), "Prediabetes and the efficacy of intervention with metformin supplement in patients with $\mathrm{BMI} \geq 23 \mathrm{~kg} / \mathrm{m}^{2}$ in Hai Phong province between 2012 and 2014" - Medical Doctor Thesis National Institute of Hygiene and Epidemiology.

4. Nguyen Van Lanh (2014). "Diabetes, prediabetes among Khmer people in Hau Giang province and assessment of efficacy of intervention methods." Medical Doctor Thesis, majoring in social hygiene and Medical Organizing Ho Chi Minh university of Medicine and Pharmacy - page $1-139$.

5. Phan Long Nhon, Dang Xuan Hao, Hoang Thi Kim Nhung (2012), "Undiagnosed diabetes in Local hospital of Bong Son, Binh Dinh". Yearbook of science $-9^{\text {th }}$ National conference of 
Endocrine and diabetes, page $22-27$.

6. Nguyen Thy Khue, Tran Minh Triet (2012), "The prevalence of diabetes and risk factors among government officers in District 10. Of Ho Chi Minh city Endocrine and Diabetes" . Yearbook of science $-9^{\text {th }}$ National conference of Endocrine and diabetes, page $22-27$.

7. Trần Ngọc Thanh (2011), “Tỉ lệ mắc tiền đái tháo đưòng và khả năng rút ngắn thời gian thưc hiện nghiệm pháp dung nap glucose”. Luận văn Thạc sĩ, chuyên ngành Sinh lý học, tr. 1 - 55.

8. Tran Ngoc Thanh (2011), "Prevalence of prediabetes and chances of cutting down on time performing glucose tolerence test." - Master Thesis, majoring in biophysiology, page $1-55$. 